\title{
Present challenges to global forests and the role of IUFRO
}

\author{
John A Parrotta
}

We live on a spectacularly rich and inspiring planet. Nowhere in this beautiful but fragile biosphere is the inspirational power of nature more striking than in our forests.

They are the reason we were in Curitiba drawn to Latin America's first IUFRO World Congress by the wonder, passion and intellectual curiosity that drives us as scientists, educators and students.

Forests - in all their amazing variety - are of vital importance for so many reasons. To start with, they are the home of an estimated $80 \%$ of the Earth's terrestrial biodiversity. While all forest types are critically important in this respect, it is worth noting that the world's shrinking rain forests, which cover less than $2 \%$ of our planet's total surface area, are home to 50\% of Earth's plants and animals.

Beyond their importance to biodiversity conservation, forests are critical to our own survival. Forests and their biodiversity have supported our own species' material, cultural and spiritual needs - for thousands of generations. Today, they directly or indirectly support livelihoods, economies, communities, and cultures worldwide. They provide a range of goods and services including timber, food, medicines and other non-timber forest products, energy and bioproducts, as well as ecological functions such as carbon storage, nutrient cycling, provision of water and air purification. Forests are also essential for the social and cultural benefits they provide, such as recreation, educational opportunities, traditional resource uses and spirituality.

Throughout history, societies and whole

\begin{abstract}
The new IUFRO President 2019-2024 Dr. John Parrotta, US Forest Service, summarizes his vision of the present challenges to global forests and the role of the International Union of Forest Research Organizations (IUFRO). This paper is drawn from his acceptance speech at the XXV IUFRO World Congress held in Curitiba, Brazil, on 29 Sept - 5 Oct 2019.
\end{abstract}

\section{Keywords: IUFRO, Global Forests, Forest Challenges}

civilizations have come and gone because they ignored the dangers of mismanagement and waste of natural resources - including forests. Sacrificing long-term sustainability for short-term gain, or just greed, seems to be a recurring pattern. This is glaringly apparent in the widespread forest destruction we have witnessed in recent decades. But this is certainly not inevitable.

A large proportion of the world's forests and their biodiversity are conserved and managed by communities to whom we are deeply indebted. I am referring of course to those indigenous and local communities around the world who take the long view, a multi-generational view. Their knowledge and wisdom continue to inspire visions of sustainability in mainstream society. Over countless generations, so many of these communities have managed to retain their rich cultural traditions, and supported their material and non-material needs, through sustainable forest and landscape management practices. They, and those who have supported their struggles, have often done so in the face of extreme pressures. They deserve our deepest respect. They deserve our support.

We face some enormous environmental and societal challenges that have serious implications for forests and all of us who depend on them - regardless of who we are or where we live.

The list is a long one, including, among others:

- climate change;

- land degradation; $\square$ US Forest Service, Research \& Development, Washington Office, 201 14th Street, SW, Washington, DC 20024 (USA)

@ John A Parrotta (john.parrotta@usda.gov)

Received: Oct 08, 2019 - Accepted: Oct 21, 2019

Citation: Parrotta JA (2019). Present challenges to global forests and the role of IUFRO. iForest 12: 488-490. - doi: 10.3832/ifor0066-012 [online 2019-11-02]

Communicated by: Elena Paoletti
- biodiversity loss and biological invasions;

- depletion of freshwater resources; and

- deforestation resulting from shortsighted and poorly planned land conversion for agriculture, infrastructure, mining, and urban development.

These threats and associated governance failures undermine the capacity of forests to provide the goods and environmental services required by the world's growing population. We see their impacts at all scales - locally, regionally and globally. They directly or indirectly create economic hardship, fuel social conflicts, and swell the ranks of environmental refugees. Is this the future we want? I don't think so.

We can do better. We must do better. And IUFRO has a very important role to play.

\section{The forest science community has a very important role to play in the world}

Through our work, and the long-range perspective that is second nature to those in our profession, the scientific community deepens our understanding of the complexities of forest systems, from molecular to continental scales. Our research shines a light on the relationships between forests and their utilization in the context of broader ecological, socio-economic and cultural landscapes. The knowledge we generate provides us with a solid, scientifically-grounded basis for assessing both the positive and negative impacts of forest management, land-use change, and technological innovation.

A good example of this is IUFRO's current work related to forest landscape restoration.

For many decades, forest scientists worldwide have focused on improving forest productivity and health, reforestation, land rehabilitation, and the impacts of changing climatic conditions. This deep pool of knowledge, reinforced by new research, particularly in the social sciences, allows us to offer scientifically sound options for forest landscape restoration to help address the climate crisis and facilitate a transition to a bio-economy built on sus- 
tainable land management practices and health rural economies.

IUFRO's current and potential audience is a very broad one. It includes, among others:

- young scientists worldwide who need a strong knowledge base to develop innovative solutions to sustain forests and their associated values;

- the children and youth who have recently mobilized millions of people at thousands of events worldwide to demand climate action;

- sustainability-minded farmers, forest owners, and entrepreneurs seeking a level playing field;

- citizens and consumers throughout the world who want to make a difference in their daily lives to help stem environmental degradation;

- civil society organizations and NGOs working in the interest of forest conservation and environmental justice; and

- responsible decision-makers at all levels who understand the connections between sustainable management of forests and broader development goals and aspirations.

The world needs what IUFRO has to offer. I believe that it is our duty - as scientists and responsible members of society to share the knowledge and insights resulting from our research to help the public, and decision-makers, to make well-informed choices. In short, to deliver the science they can use.

But this is not an easy task. There is a lot of noise and misinformation out there, competing for people's attention.

To fulfill this role in these challenging times, we need to ask, and answer, the right questions in our research. We must also make the results of our work widely available to a broad range of decision-makers and the general public.

Asking the right questions means taking into consideration societal needs and future trends when formulating our research questions, methodologies, and analyses.
We can accomplish this by framing our often highly specialized research and our scientific syntheses in terms of broader sustainable development challenges - such as those articulated in the 2030 Agenda and the Sustainable Development Goals.

In doing so we can better convey to our stakeholders the value of our science and its utility to society. Providing this broader context - built on a solid foundation of indepth research - enhances the effectiveness and expands the range of our communications efforts.

The good news is that IUFRO is already providing this service to society through its publications, podcasts, webinars and other communications efforts (Fig. 1).

Our Scientific Summaries, World Series, Occasional Papers, IUFRO News and IUFRO Spotlights, Press Releases, the IUFRO Blog and our Facebook page provide a very large and diverse audience with highly relevant and accessible summaries of forest research by IUFRO member organizations, officeholders and units.

One of our most effective mechanisms for addressing the needs of policy-makers is through our Global Forest Expert Panels (GFEP). GFEP reports and policy briefs provide objective, independent, and multidisciplinary scientific assessments of key issues, to support more informed decision-making at the global level. These assessments and policy briefs are highly regarded in international policy circles and receive extensive media coverage globally.

IUFRO's outreach efforts - as well as our engagement in regional and global forestrelated policy forums - need to continue and expand. In my role as President, I am fully committed to supporting IUFRO's current and emerging communications and policy engagement initiatives.

\section{Diversity - IUFRO's strength}

The productivity, health, and the many benefits we derive from forests are underpinned by biodiversity. Likewise, IUFRO's scientific excellence, creativity and value to society depends on engaging the diversity of our member organizations and scientists. Diversity of disciplinary perspectives, knowledge, experience, and cultural values.

IUFRO has a long and very rich history going back 127 years to its European roots. In recent decades we have made tremendous progress in diversifying the geographical, cultural, and disciplinary scope of our membership and activities. Today, IUFRO's network includes nearly 650 member institutions in 127 countries.

However, we still have work to do to improve the gender balance and representation of scientists of all ages from many parts of the world, at all levels of our organization. As Mike Wingfield and other recent Past-Presidents have done so effectively, I will continue to prioritize inclusiveness during my Presidency. I will be highly supportive of, and engaged in, ongoing and new initiatives to expand the involvement of students and young scientists, women, and scientists from currently under-represented regions of the world, in our work.

As I mentioned earlier, the sustainable development challenges we face are multifaceted, and extend beyond the traditional scope of forest science.

The good news is that we are not alone. IUFRO can multiply its impact by expanding our collaboration in research, science synthesis and communications well beyond the boundaries of our current network. Over the next 5 years, I will work to foster greater collaboration with scientists and research networks that can help us better leverage our impact and broaden our knowledge and research capabilities. This may include, for example, fields such as agriculture, medicine, spatial planning, environmental engineering, bio-refinery and chemistry, environmental education, the arts and humanities.

Our dedicated and creative leaders in IUFRO's nine disciplinary Divisions, as well as our Task Forces, Special Programs and

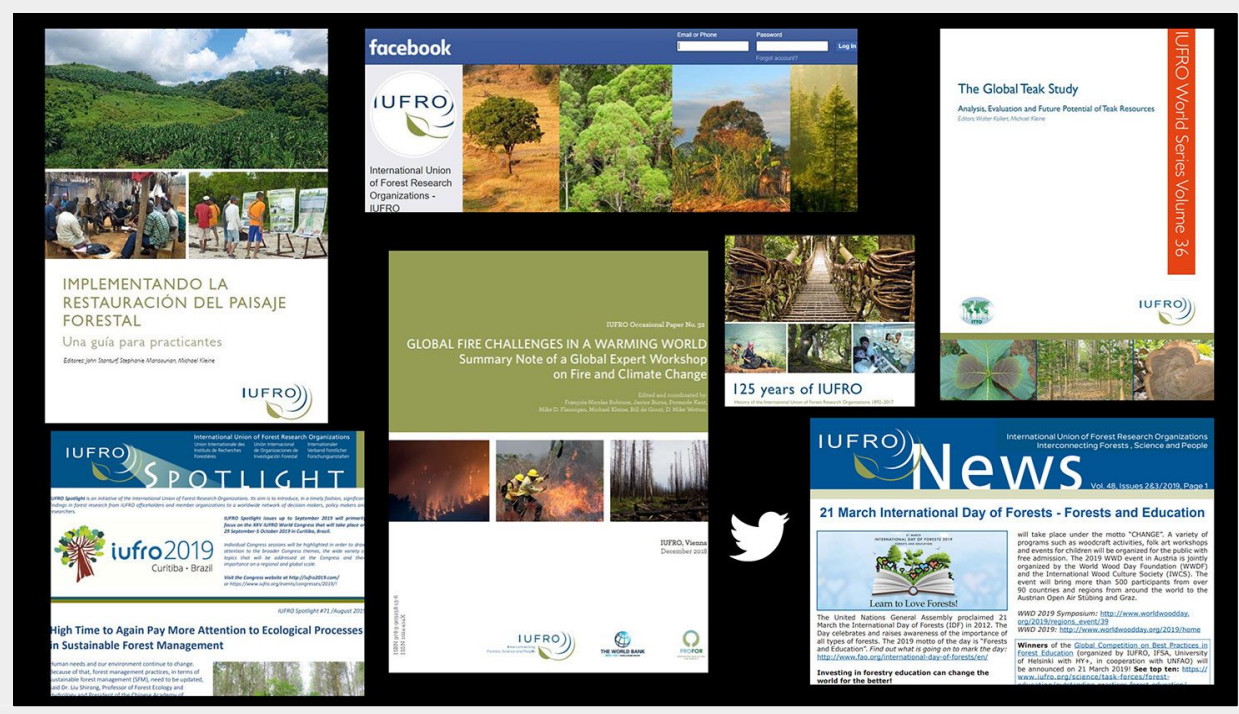

Fig. 1 - Examples of IUFRO's outreach activities. 
Projects, are all well-positioned to lead such outreach efforts to our academic and professional colleagues in other fields. They can count on my enthusiastic support in these efforts.

\section{Concluding remarks}

We are living in a time of rapid environmental, economic, social and technological change. These changes present critical multi-dimensional challenges for forests, and people. The global scientific community represented by IUFRO already has the knowledge needed to face many of these challenges.

To fully realize our potential, however, we need to better harness the knowledge, expertise and creativity within our network through greater integration of scientists and IUFRO member organizations. We also need to expand our collaborative relationships well beyond the boundaries of forest science and broaden our communications and outreach activities. In doing so IUFRO can - and will - truly interconnect, forests, science and people for a better world.

I look forward to the honor, and challenge, of leading this effort as IUFRO's President. And I assure you that I will do all I can to support the incredible diversity of activities and initiatives that will be undertaken within our global network during these next five years. 